\title{
Impactos ambientales de la colonización agrícola en Coto Brus, Costa Rica (1940-2018)
}

\author{
Environmental impacts of the agricultural colonization in \\ Coto Brus, Costa Rica (1940-2018)
}

\author{
Adolfo Quesada-Román ${ }^{l}$ \\ University of Geneva, Suiza \\ Universidad de Costa Rica, Costa Rica \\ Ronald Díaz-Bolaños ${ }^{2}$ \\ Universidad de Costa Rica, Costa Rica \\ Universidad Estatal a Distancia, Costa Rica.
}

\begin{abstract}
Resumen
Coto Brus es un cantón al sureste de Costa Rica, funge como un crisol de culturas indígenas, costarricenses, panameñas e italianas que modelaron su territorio durante los últimos setenta años. El objetivo del presente trabajo es analizar el impacto ambiental de la colonización agrícola de Coto Brus y los cambios en el paisaje experimentados en su territorio a partir de 1940. Este estudio pone en evidencia la otra cara del explosivo desarrollo que tuvo Coto Brus en sus primeras décadas de existencia y además cómo los patrones multiculturales privaron en el crecimiento de la frontera agrícola en una de las regiones menos estudiadas del país. La metodología se basa en una revisión documental de diferentes fuentes bibliográficas entre libros, artículos, relatos históricos y legislación. A partir de un análisis geográfico histórico se lograron determinar tres periodos históricos que sintetizan el impacto en el medioambiente de las actividades productivas durante más de siete décadas.
\end{abstract}

Palabras clave: Costa Rica, Coto Brus, medioambiente, colonización, café.

1 Climatic Change and Climate Impacts, Institute for Environmental Sciences, University of Geneva, adolfo. quesada@unige.ch.Escuela de Geografía, Universidad de Costa Rica, adolfo.quesadaroman@ucr.ac.cr

2 Centro de Investigaciones Geofísicas y Escuela de Estudios Generales, Universidad de Costa Rica, ronald. diaz@ucr.ac.cr.Escuela de Ciencias Sociales y Humanidades, Universidad Estatal a Distancia de Costa Rica. 


\begin{abstract}
Coto Brus is a canton in southeast Costa Rica, serving as a melting pot of indigenous, Costa Rican, Panamanian and Italian cultures that shaped their territory during the last seventy years. The objective of this paper is to analyze the environmental impact of the agricultural colonization of Coto Brus and the resulting changes in the territory's landscape experienced since 1940. This study exposes the other side of the explosive development that took place in Coto Brus during its first decades of existence as a canton and also highlights how multicultural patterns deprived the growth of the agricultural frontier in one of the least studied regions of the country. The methodology is based on literature review of different bibliographical sources such as books, articles, historical accounts and legislation. By means of a historical geographical analysis, three historical periods were determined which synthesize the environment impacts brought by productive activities for more than seven decades.
\end{abstract}

Keywords: Costa Rica; Coto Brus; environment; colonization; coffee.

\title{
Introducción
}

El cantón de Coto Brus se constituye en el año 1965, en un territorio que desde hacía siglos había sido habitado por poblaciones indígenas de procedencia chibcha, a la que luego se sumaron colonos procedentes de Chiriquí, en la vecina Panamá durante el siglo XIX e inicios del XX y, posteriormente, numerosas familias costarricenses provenientes principalmente del Valle Central a partir de la década de 1940. Las condiciones de clima, relieve y suelos hicieron posible que el territorio cotobruseño se poblara y se convirtiera en un espacio privilegiado para el desarrollo del cultivo del café, en particular con la fundación de Sabalito y de la colonia italiana de San Vito de Java en la década de 1950, asentamiento que se convertiría en la cabecera del floreciente cantón.

No obstante, la expansión del café y de otras actividades agropecuarias se dio paralelo a un aumento de la deforestación por el desmonte de tierras y su transformación, principalmente en fincas cafetaleras y ganaderas, proceso que llegó a su punto culminante en los decenios de 1970 y 1980. Aun así, las políticas ambientales impulsadas a finales del siglo XX han favorecido la recuperación de los bosques y la protección de las áreas menos alteradas por la presencia humana fruto de un intenso proceso de ocupación del espacio. Por eso, el presente trabajo analiza los impactos causados por la colonización agrícola en el medio ambiente en el territorio de Coto Brus desde la década de 1940 hasta mediados del segundo decenio del siglo XXI. 


\section{Aspectos geográficos del cantón de Coto Brus}

Coto Brus es un cantón que pertenece a la provincia de Puntarenas, localizado en la Zona Sur del país, o región Brunca. En el marco político administrativo limita al norte con Talamanca (provincia de Limón), al sureste con la frontera con Panamá, así como con el cantón de Corredores y al oeste con los cantones de Buenos Aires, Golfito y Osa (Chinchilla, 1987). Su extensión territorial es de $933 \mathrm{~km}^{2}$, el cual consta en la actualidad de seis distritos: San Vito, Sabalito, Agua Buena, Limoncito, Pittier y Gutiérrez Braun (Mapa 1). Se sitúa en una depresión intermontana, a la que se la ha dado el nombre de Valle de Coto Brus, formada en su mayoría de flujos de detritos producto de una fuerte influencia tectónica y volcánica del pasado de la Cordillera de Talamanca al norte. Además, limita con la Fila Brunqueña al sur, la cual es producto de la formación de un antearco sedimentario de edad miocénica (entre 27 y cinco millones de años antes del presente).

La cabecera cantonal, San Vito, se ubica junto al río Java, en un altiplano situado a 1100 m.s.n.m., cuya superficie presenta un carácter predominantemente plano y ondulado junto con espacios interfluviales amplios que superan los $200 \mathrm{~m}$ de ancho. La ciudad se localiza a $8^{\circ} 50^{\prime}$ de Latitud Norte y $82^{\circ} 59^{\prime}$ de Longitud Oeste, posee una temperatura media anual de $20,7^{\circ} \mathrm{C}$ y $3808 \mathrm{~mm}$ anuales de precipitaciones que se producen principalmente entre los meses de mayo y noviembre; debido a sus condiciones climáticas y edáficas, constituye un espacio propicio para el desarrollo del cultivo del café que es precisamente uno de sus principales productos (Morales \& Romero, 2000).

El cantón de Coto Brus se empieza a colonizar en forma masiva a partir de la definición de los límites territoriales entre Costa Rica y Panamá en 1940. En esta frontera viva han convergido grupos indígenas (actualmente representados por los ngöbes y buglés que han migrado desde $\mathrm{Pa}$ namá), colonos panameños y costarricenses que han modelado los paisajes montañosos de dicha región desde antes de los tiempos coloniales. En un inicio, la creación de los poblados de Cañas Gordas, Agua Buena, Sabalito y San Vito se dio por la apertura de trochas en medio del bosque, construcción de caminos, el impulso de la frontera agrícola propiciado desde Chiriquí y la colonización rural extranjera por parte de inmigrantes italianos 


\section{Mapa 1: Distritos y algunos poblados del cantón de Coto Brus}

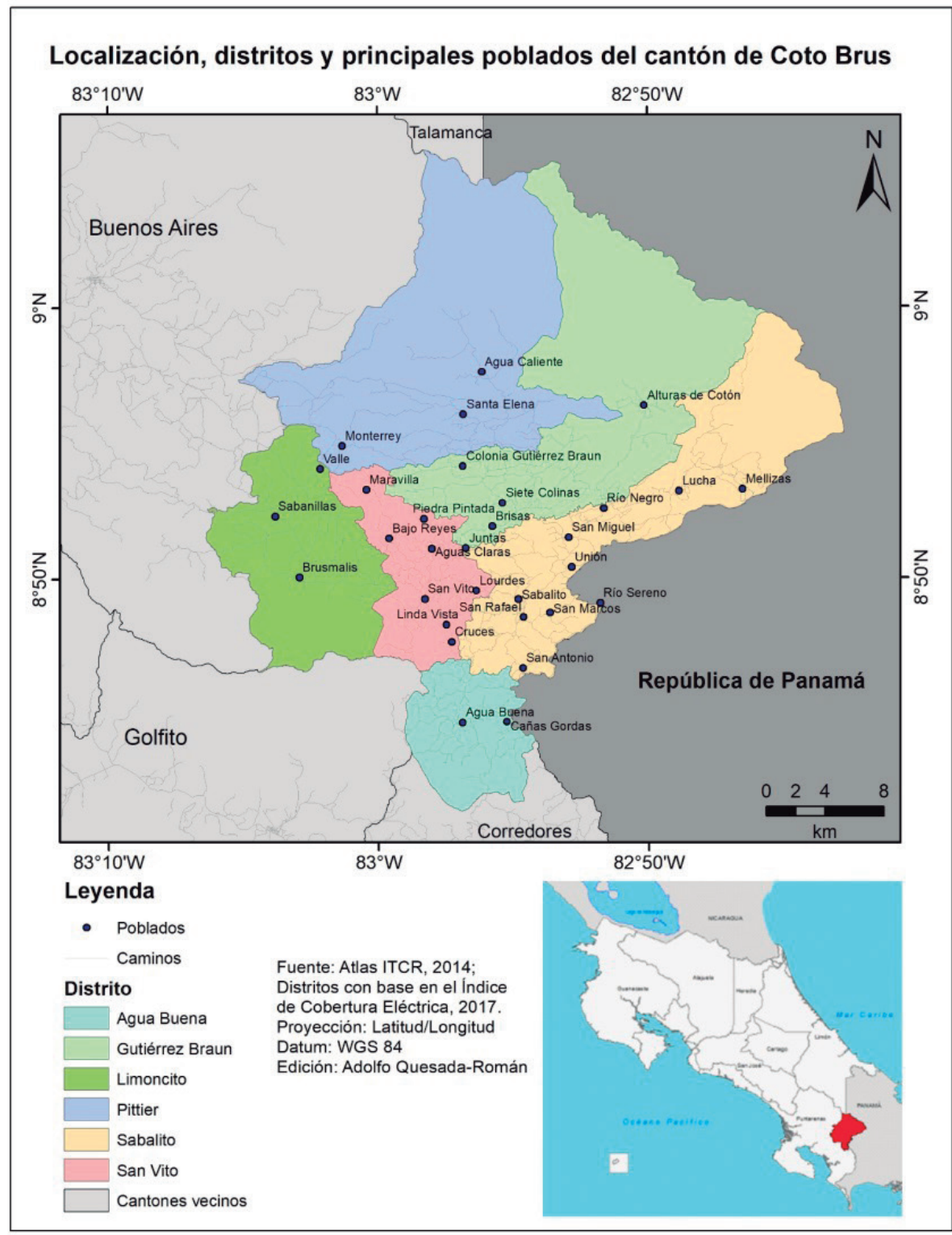


que fue planificada en conjunto por los gobiernos de Costa Rica y de Italia en 1952.

El desarrollo de esta región y su panorama actual está marcado por cambios drásticos en el paisaje, basados en la deforestación desmedida, la agricultura (especialmente del café), la ganadería (leche y carne), y por último la urbanización, mediante el establecimiento de pueblos y ciudades de pequeñas dimensiones dentro del marco regional y nacional. No obstante, la creación de áreas de conservación, corredores biológicos y la promulgación de leyes ambientales durante la década de 1990, así como la concientización ambiental de su población ha invertido esta condición en los últimos 18 años.

\section{Metodología}

El presente artículo comprende dos fases, la primera constituye una revisión bibliográfica de varias obras relacionadas con el desarrollo histórico y la problemática ambiental presentes en el cantón de Coto Brus, ubicado en el sureste de la República de Costa Rica, a partir de diferentes fuentes bibliográficas entre ellas libros, artículos, relatos históricos y legislación. De estas fuentes se extrajeron los datos concernientes al proceso de colonización agrícola de este cantón y los impactos ambientales que han sido documentados en ellas.

Una segunda fase se compone de la determinación de tres periodos históricos que sintetizan el impacto en el medio ambiente de las actividades productivas durante más de siete décadas de desarrollo del cantón de Coto Brus; primera etapa de colonización anterior al cantonato (1940-1965), la consolidación de la agroindustria cafetalera en Coto Brus (1965-1990) y la diversificación de la actividad productiva en Coto Brus (1990-2018). Este abordaje se hace basado en el análisis geográfico de las características físico-geográficas y socioeconómicas del cantón que favorecieron el impacto ambiental durante las primeras décadas de su conformación y, posteriormente, como las políticas ambientales en la década de 1990 contribuyeron con la protección de los ecosistemas. 


\section{Resultados}

\section{El paisaje de Coto Brus en la época anterior al cantonato}

Desde el punto de vista geográfico, el territorio del actual cantón cotobruseño incluye una parte significativa de la depresión intermontana irrigada por el río Coto Brus y sus afluentes, del cual el cantón toma su nombre, no obstante este nombre deriva de la palabra Couto, Coctú, Cooto o Cobto, la cual fue una provincia indígena localizada al sureste de Quepos, mientras que el término Brusi era una parcialidad teribe o de indios del norte; nombre que luego evolucionó a Brus, el cual se asignó a un valle de Boruca (Gagini, 1917). Este espacio fue descrito de la siguiente forma por el autor Jorge León Arguedas (1916-2013), en el que se resaltan aspectos relacionados con las condiciones geográficas que caracterizaron el paisaje que encontraron los primeros pobladores que arribaron a dichas tierras, aunque denomina mesetas a las superficies más llanas que lo componen: "El curso superior del río (Coto) Brus está formado de mesetas extensas, que descienden suavemente hacia el litoral, cubiertas por sabanas o bosques claros. El suelo laterítico es fértil, con aguas abuntantes" (León, 1952, p. 162). La fertilidad del suelo y la topografía relativamente plana hacían de esta zona un espacio propicio para el desarrollo agrícola.

Históricamente, estas tierras fueron habitadas entre unos $6000 \mathrm{y}$ 3000 años a. C. por poblaciones originarias que antecedieron a los cotos, una subdivisión de la etnia brunca o boruca, cuyos descendientes fueron finalmente confinados en el pueblo de indios de Boruca durante el período colonial (Edelman \& Seligson, 1994; Araya, 2017). De hecho, Clement \& Horn (2001) determinaron que en la Laguna Zoncho en Linda Vista de San Vito la presencia de carbón, polen de maíz y fragmentos de artefactos en las muestras del núcleo de sedimentos lacustres tomadas por paleoecólogos, así como artefactos excavados por arqueólogos del área cercana al lago, indican una ocupación humana casi continua de la cuenca del lago durante más de 3000 años. La evidencia muestra que la corta y quema del bosque por parte de los agricultores prehistóricos fueron más evidentes entre aproximadamente 1240 a.C. y 1540 d.C.

En tiempos más recientes el territorio del actual Coto Brus ha sido habitado por las etnias ngöbe y buglé, pueblos transfronterizos de origen chibcha que se instalaron principalmente en las secciones montañosas y mantienen un activo intercambio con sus lugares de origen en Panamá; 
además de la presencia de colonos mestizos procedentes de la provincia panameña de Chiriquí, quienes desde el siglo XIX se habían establecido y fundado poblados en distintos puntos de la Zona Sur de Costa Rica, los cuales mantenían un activo intercambio económico con las tierras de donde son originarios (Naranjo, s.f.; Morales \& Romero, 2000; Amador, 2008; Morera \& Meléndez, 2017).

El Camino Real, más conocido como Camino de Mulas, que a partir de 1601 facilitó la comunicación terrestre y el intercambio de productos entre Costa Rica y las provincias vecinas de Veragua y Panamá, atravesaba el Valle de Coto Brus, recorría el sitio conocido como Cañas Gordas y continuaba hasta Santiago de Alanje en la actual Panamá. A pesar de ser una vía terrestre relativamente utilizada, comenzó a perder importancia debido a los cambios económicos experimentados en el comercio transístmico panameño en el siglo XVIII y dado el escaso mantenimiento que se le dio, se deterioró y perdió relevancia como vía de comunicación en los años posteriores al proceso de independencia (Naranjo, s.f.).

Uno de los primeros asentamientos chiricanos fue Cañas Gordas, actualmente ubicado en la frontera entre Costa Rica y Panamá, que a inicios del siglo XX estaba habitado por las familias de Maximiliano Peralta y Pedro Rodríguez Rebolledo (Chinchilla, 1987). El término Cañas Gordas pasó a denominar también a todo el espacio que comprendió el asentamiento del mismo nombre, que incluyó tierras que hoy día se ubican en los cantones de Buenos Aires y Coto Brus y que fue objeto de varios denuncios de tierras (Araya, 2017). Este territorio fue visitado en 1896 por el naturalista suizo Henri Pittier (1857-1950), en ese entonces director del Instituto Físico-Geográfico Nacional (1889-1904), como parte de un viaje de exploración para recabar datos con el propósito de actualizar la cartografía existente en Costa Rica, en el que rectifica algunas nociones que existían de esa zona escasamente habitada:

Cañas Gordas no es una llanura y no tiene la extensión que se le ha atribuido, la sabana ocupa la parte superior de las colinas; raras veces su anchura pasa de 100 metros y su altura es de poco más o menos 1.200 metros sobre el nivel del mar, esto es, ligeramente superior a la de San José. En los vallados que la rodean, hay ciénagas extensas, que demuestran una flora particularmente interesante. En estas ciénagas nacen todas las aguas de la región, las que son recogidas principalmente por las cabeceras de los ríos 
Colorado y Corredor y en su menor parte por la quebrada de la Vuelta, afluente del Chiriquí Viejo. En el punto de vista económico, la sabana tiene muy poco valor, el suelo es casi enteramente formado de laterita (tierra roja), seca, compacta y estéril y cubierta solamente por Gramíneas duras y otras plantas velludas y semi-leñosas (Instituto Geográfico Nacional, 1989, p. 129).

A raíz de la significativa presencia chiricana y a la indefinición limítrofe que existió entre Costa Rica y Panamá a comienzos del siglo XX, el pequeño poblado de Cañas Gordas, albergó un corregimiento perteneciente a la provincia de Chiriquí, que ejercía su jurisdicción sobre unas familias dedicadas a la agricultura de subsistencia y que se comunicaba con el asentamiento de Pueblo Nuevo de Coto, próximo a la desembocadura del río Coto Colorado, a través de "caminos difíciles de recorrer" debido a que atravesaban la Fila de Cal y se deterioraban con facilidad durante la estación lluviosa dadas las escasas posibilidades de mantenimiento (Sánchez, 2011, p. 161).

Samper \& Peters (2001, p. 69) describen algunos de los cambios introducidos por los habitantes que poblaban el Valle de Coto Brus: "Los primeros colonizadores mestizos costarricenses y panameños, así como sus predecesores indígenas, habían hecho abras para milpas y tapaderos de frijol. También sembraron pastos para sus vacunos y equinos en una zona prometedora pero remota y mal comunicada". Es decir, estas poblaciones roturaron pequeñas extensiones de tierras cubiertas de bosques para dedicarlos a una agricultura de subsistencia, sea para el consumo propio como para el intercambio con pobladores de las zonas costeras del Pacífico Sur.

La conveniencia de establecer un puerto en el Golfo Dulce, específicamente en el sitio conocido como Golfito, fue señalado en un informe emitido por Víctor Guardia Quirós (1873-1959), tras un viaje emprendido a las costas del sur del país en marzo de 1913, lo que haría más accesible la comunicación "hasta donde desciende en gradiente lento el Cerro de la [sic] Cruces, que es un estribo de la alta meseta de Cañas Gordas" (Naranjo, s.f., p. 13). Por tanto, esto facilitaría el proceso de ocupación de la tierra para colonos procedentes del Valle Central y otras zonas del país.

Un testimonio de la época, escrito por el viajero finlandés Håkan Arvid Mörne (1900-1961), quien visitó Costa Rica procedente de Panamá en 1948, describe el paisaje de la zona de Agua Buena, que en ese momento 
era una finca donde luego surgiría una de las principales poblaciones del cantón cotobruseño:

Pronto llegamos a la solitaria finca ganadera de Agua Buena. En un edificio pequeño y bonito, que quedaba a la orilla de un arroyo susurrante, nos volvió a saludar ese amistoso oficial de policía. Nos llevó directo a una mesa servida y nos dijo que nos sintiéramos en Costa Rica como en nuestra propia casa [...] El oficial de fronteras nos condujo a un puesto de vigilancia en la cima de una loma talada. Caminamos por los potreros de la finca y por un riachuelo arcilloso al pie de la loma. El oficial me comentó que él mismo había levantado esa finca, para poder aguantar la soledad [...] En la fresca mañana mantuve un paso rápido por la carretera recién construida [por Fila de Cal hacia Corredor], diseñada con suaves curvas entre lomas boscosas. Agua Buena estaba a más de mil metros de altura y no había notado ninguna depresión en el terreno durante las primeras horas (Mörne, 2001, p. 747-750).

Debido a la escasa población que habitaba las tierras del Valle de Coto Brus hacia mediados del siglo XX, el paisaje estaba constituido básicamente por bosques que empezaban a ser talados para el cultivo de productos de subsistencia o la apertura de pequeñas fincas ganaderas que paulatinamente irían reduciendo las tierras forestales a los terrenos montañosos y de más difícil acceso, como sucederá también con otras zonas fronterizas del país que estaban siendo ocupadas en esa época (Díaz \& Salazar, 2017).

\section{Primera etapa de colonización del cantón de Coto Brus (1940-1965)}

El proceso de colonización de la Zona Sur de Costa Rica fue el resultado de la expansión meridional de la frontera agrícola hacia la Zona de los Santos y el Valle de El General durante las últimas décadas del siglo XIX y las primeras del siglo XX y da como resultado la ocupación de dichos espacios, su transformación en zonas de cultivo y la fundación de asentamientos como San Marcos de Tarrazú, Santa María de Dota, San Isidro de El General y Buenos Aires (Hilje, 1991).

Las tierras que conforman el actual cantón de Coto Brus, se encontraban escasamente pobladas y empiezan a ser objeto de un mayor interés para los colonos procedentes del interior del país a inicios de la década de 
1940, cuando los gobiernos de Costa Rica y Panamá comienzan la demarcación de su frontera común, por lo que se pone fin a una disputa territorial de varios decenios (Sibaja, 1968; Díaz, 2013). Desde un punto de vista político-administrativo, las actuales tierras cotobruseñas estaban divididas entre los cantones de Golfito y Buenos Aires y a su vez, estos dos cantones habían sido desmembrados del cantón de Osa, fundado en 1914, que abarcaba todo el territorio y las poblaciones del sur de Costa Rica hasta la disputada frontera con Panamá y cuya cabecera se encontraba en la ciudad de Buenos Aires (Arias, 2007-2008; Instituto Geográfico Nacional, 2009).

Debido al avance de la frontera agrícola en las zonas periféricas de Costa Rica, que se experimentó hacia mediados del siglo XX, flujos de población campesina procedente del Valle Central se dirigieron hacia el sur del país, aspecto que se vio favorecido por la apertura de la Carretera Interamericana, y se establecieron en el Valle de Coto Brus, porque en el proyecto original esta vía de comunicación hacía el enlace con Panamá a través de este espacio, que poseía las condiciones idóneas para el desarrollo de la actividad cafetalera y de otros productos agrícolas que abastecieran a las plantaciones bananeras al sur de la Fila de Cal (Sánchez, 2011). El desarrollo del enclave bananero en el Pacífico Sur estimuló la colonización de las tierras cotobruseñas, a partir de la apertura de los puertos de Quepos (1939) y Golfito (1941), a lo que se sumó la construcción del camino que comunicaba esta localidad portuaria con Agua Buena y Cañas Gordas, a través de la Fila de Cal, lo que hizo posible el transporte de la maquinaria que se emplearía en el desmonte de las tierras donde se iba a trazar la Carretera Interamericana (Naranjo, s.f.; Ministerio de Cultura, Juventud y Deportes \& Centro de Investigación y Conservación del Patrimonio Cultural, 1990).

En este contexto de ocupación del Valle de Coto Brus surgieron asentamientos como Colonia Sabalito, próximo a la recién demarcada frontera con Panamá, que fue originalmente un campamento para los trabajadores que construyeron la Carretera Interamericana al que se trasladaron campesinos, quienes debieron acceder a él viajando desde el Valle Central hasta Puntarenas por medio del Ferrocarril Eléctrico al Pacífico y de allí tomar una embarcación que los llevara a El Pozo - hoy día Ciudad Cortés - o Golfito; el viaje continuaba en tren por el Ferrocaril del Sur hasta Punta Riel - llamada posteriormente Villa Neily y hoy día Ciudad Neily - y de allí por tierra que los llevaría por el camino que atraviesa la Fila de Cal hasta 
llegar al poblado (Ministerio de Cultura, Juventud y Deportes \& Centro de Investigación y Conservación del Patrimonio Cultural, 1990).

Para finales de la década de los cuarentas, a la llegada de los pioneros costarricenses al poblado de Sabalito, dio inicio la labor de limpieza de la montaña, con el fin de obtener sus propias fincas y luego trabajarlas para sí y vender sus productos en las plantaciones bananeras de la costa. Este pueblo empezó a crecer muy rápido, se constituyó en un punto bastante atractivo para los emigrantes del Valle Central en búsqueda de tierras que colonizar. Los colonos empezaron a sembrar diversos cultivos, principalmente chayote, arroz, maíz, frijoles y hortalizas, en especial rábanos y repollos (Ministerio de Cultura, Juventud y Deportes \& Centro de Investigación y Conservación del Patrimonio Cultural, 1990 Díaz \& Quesada-Román, 2016).

Al mismo tiempo, se dio un proceso de especulación y acaparamiento de tierras que llamó la atención de la opinión pública en el decenio de 1940 y motivó la intervención del diputado vanguardista y escritor Carlos Luis Fallas (1909-1966), quien abogó por la indenunciabilidad de 10000 hectáreas de tierra en los alrededores de Sabalito para que sus pobladores pudieran cultivarlas y con ello se libraban de las actividades especulativas que estaban siendo objeto (Naranjo, s.f.).

El Estado estimuló las actividades productivas de los campesinos de Sabalito por medio del Ministerio de Agricultura, entidad que les notificó que debían aprovechar las condiciones que hacían propicio el cultivo del café, como lo eran la ubicación de la zona que habitaban entre los 1000 y 1200 metros de altura la alta calidad de los suelos de origen volcánico característicos de la sección sureste del cantón (Gutiérrez, 2002). Estos factores fueron determinantes en el creciente interés de los sabaliteños por la siembra de café a mayor escala, mediante la adquisición de almácigos proporcionados gratuitamente por las mismas autoridades, y se dieron relaciones de ayuda mutua entre los mismos colonos tendientes a garantizar un crecimiento equilibrado del pueblo. Fue gracias a la fertilidad de los suelos y a las condiciones naturales que encontraron en Coto Brus, que se dio la siembra del cafeto, al que se le agregó sombra con el cultivo de bananos, y se fueron relegando algunos productos que al inicio fueron importantes, como el arroz y algunas hortalizas, siempre consumidas, pero ahora producidas a una escala menor. 
No obstante, la modificación del trazado de la ruta de la Carretera Interamericana que se efectuó en 1954, dispuso que la vía definitiva se trazara al sur de la Fila de Cal, lo que favoreció a las poblaciones surgidas en el enclave bananero del Sur - entre ellas la actual Ciudad Neily - y significó un importante escollo para los campesinos que se habían asentado en la zona ubicada al norte de este sistema montañoso, que habían sido atraídos por la construcción de dicha vía en las tierras del actual cantón de Coto Brus, según el convenio firmado en 1945, por lo que estos colonos debieron afrontar el impacto económico generado por el cambio en el trazado de esta carretera, especialmente en cuanto a la comercialización de sus productos (Sánchez, 2011; Araya, 2017).

De acuerdo con Gutiérrez (2002), los problemas que sufrieron los sabaliteños fueron grandes a la hora de sacar sus primeras cosechas de café porque la distancia con Punta Riel era de 33 kilómetros, pero se demoraba mucho tiempo debido a lo sinuoso de la vía y los caminos normalmente se encontraban anegados por las difíciles condiciones climáticas de setiembre hasta noviembre. Se trató de sacar el café a caballo hasta Campo Tres, luego de allí se transportaba en un camión propiedad de Ernesto Araya hasta Punta Riel y por medio de vehículos contratados se enviaba por la Carretera Interamericana hasta Pérez Zeledón y luego al Valle Central.

El costo del transporte entre Sabalito y la capital era muy caro y no sacaban buenos precios al final por llevar el café sin procesar: el primer grano que sacaron los sabaliteños lo secaban en manteados que usaron anteriormente para secar arroz y frijoles y resultaba una limitante su procesamiento con tecnología rudimentaria basada en el empleo de una chancadora y una tostadora. Muchos de esos primeros caficultores optaron por no producir más ante la odisea que representaba sacar el grano hasta el Valle Central.

En este contexto emerge la figura de Luis Wachong Lee, un empresario de origen chino que instaló en Sabalito un beneficio de café entre 1955 y 1956, pero faltaba dentro de los colonos un mayor espíritu de unión, para lograr la superación de la crisis generada por el nuevo trazado de la Carretera Interamericana y ganar mejores precios con la venta de su producción cafetalera. De aquí sale la iniciativa de crear Coopesabalito, una idea que ganó adeptos al entender que se podían obtener varios insumos sin pagar impuestos y otras garantías que hizo crear un comité organizador integrado 
por varios caficultores como José Antonio Rojas, Herminio Zumbado, Marciano Barrantes, Joaquín Chavarría y otros, quienes se dieron a la tarea de difundir el proyecto y vincular al mayor número posible de socios donde muchos no tenían ni idea de que era una cooperativa. Para 1964 se logró conformar la cooperativa con 155 socios, Luis Wachong fue uno de ellos y poco a poco fue cediendo su beneficio a la organización, como ocurrió más adelante con buen éxito (Gutiérrez, 2002).

Mientras los caficultores de Sabalito se organizaban para superar sus dificultades económicas, en la década de 1950, inició uno de los proyectos de colonización extranjera más exitosos en Costa Rica: el Ministro de Agricultura e Industrias, Ing. Claudio Volio Guardia (1918-2014), en representación del Gobierno de la República de Costa Rica y el señor Vito Sansonetti (1916-1999), representante de la Sociedad Italiana de Colonización Agrícola (SICA) firmaron el Contrato-Ley 1316 el 12 de julio de 1951 con el propósito de fomentar el establecimiento de agricultores italianos en el Valle de Coto Brus, así como incrementar los vínculos sociales y económicos que existen entre los pueblos de Italia y Costa Rica. Dicho contrato disponía la adjudicación de 10000 hectáreas de tierras pertenecientes al Estado o a los baldíos nacionales en el sur del país con la idea de impulsar el desarrollo agrícola de la zona (Sistema Costarricense de Información Jurídica, s.f.).

La llegada de estos inmigrantes italianos se dio a partir de 1952, por lo que se establecieron relaciones económicas y sociales entre estos colonos europeos y los campesinos costarricenses, las cuales se tradujeron en nuevas actividades productivas y en el desarrollo de un incipiente centro urbano que se especializaría en la producción de café: San Vito de Java (Figura 1). De acuerdo con la historiadora Rita Bariatti, el proceso de colonización de San Vito se caracterizó por ser producto de una "inmigración familiar planificada, provenientes de la Italia problemática de posguerra, los colonos presentaron una gran heterogeneidad en la procedencia regional y en la ocupación previa. La colonización los canalizó hacia un nuevo trabajo común, conformando terratenientes dedicados casi exclusivamente al cultivo del café" (Bariatti, 1989, p. 111). 
Figura 1: Centro de San Vito al inicia de la colonización agrícola

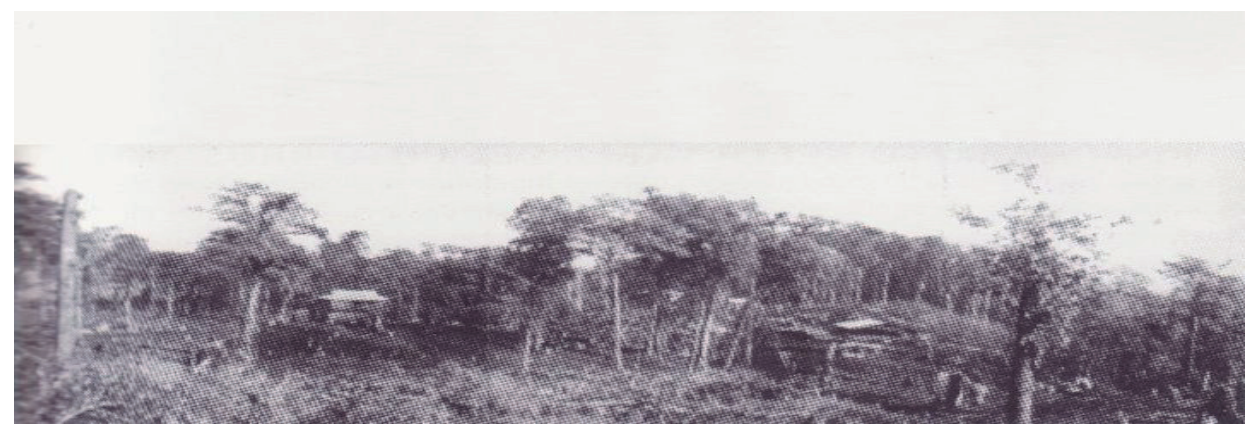

Fuente: Archivo de la Sociedad Dante Alighieri, San Vito.

El nuevo asentamiento de San Vito, ubicado a menos de ocho kilómetros al oeste de Sabalito, fue habitado tanto por colonos italianos como costarricenses que trabajaban en las fincas de café sembradas por los europeos en esa localidad, así como en El Danto y Los Reyes, y su población crecía rápidamente con el paso de los años (Ministerio de Cultura, Juventud y Deportes \& Centro de Investigación y Conservación del Patrimonio Cultural, 1990; Díaz \& Quesada-Román, 2016). Como lo apunta Carolyn Hall (1983, p. 172), mientras se mantuvo el trazado original de la Carretera Interamericana en el Valle de Coto Brus, esta ofrecía "una salida hacia los cercanos enclaves de plantaciones, tanto en Costa Rica como en Panamá, donde existía un mercado potencial para frutas frescas, verduras y productos lácteos". Sin embargo, el cambio en la ruta incidió en la orientación productiva de los habitantes de San Vito hacia el café, que era el cultivo más viable dadas las condiciones físicas de la zona.

En 1955 la colonia de San Vito recibió un importante préstamo por parte del Export-Import Bank por \$161.000, al que le siguió uno del antiguo Development Loan Found (DLF) -actual Agencia para el Desarrollo Internacional de los Estados Unidos (AID)- por \$1.250.000 en 1958; ambos préstamos fueron cancelados respectivamente e invertidos para impulsar el desarrollo económico y urbano de la incipiente población. Para el año de 1955 se empezó la construcción del aeropuerto, el Gobierno aportó 250.000 colones de un valor de 1.000 .000 de colones para la obra que se construyó en diez semanas. Este aeropuerto fue vital para la terminación 
del beneficio San Vito de la SICA, con el arribo de los cargamentos de cemento y combustible traídos en avión (Sansonetti, 1995).

La construcción del aeropuerto de San Vito significó para la naciente colonia la presencia de una vía de comunicación que compensaba la falta de caminos adecuados que la comunicara con el resto del país. De acuerdo con Ugo Santonetti (1919), uno de los pioneros de San Vito:

En una región donde de marzo a noviembre llovía inexorablemente todos los días y caían en aquel entonces, cuatro o más metros de agua al año, las trochas transitables con camiones sólo en los meses de verano, se transformaban durante esa larga estación en ríos de fango. Ni siquiera una carreta podía ser arrastrada y solamente los bueyes podían pasar con dificultad llevando atada entre los cuernos una preciada bolsa de harina.

Sin embargo, para la mayoría de los pioneros el aislamiento no actuó como factor deprimente sino como estímulo para una valerosa determinación. Nuestra respuesta al inexorable encierro fue la construcción del aeropuerto. Tuvimos que remover más de 300.000 metros cúbicos de tierra para cortar cerritos y rellenar bajos (Ministerio de Cultura, Juventud y Deportes \& Centro de Investigación y Conservación del Patrimonio Cultural, 1990, p. 78).

La SICA se encargó de la construcción de los primeros edificios públicos de la colonia, entre ellos la clínica, la escuela y la iglesia. Para los inicios de San Vito, los productos más importantes eran la madera que se comercializaba muy bien en la zona baja con la compañía bananera, igualmente, el café con un beneficio rápidamente construido fue un medio importante de ingresos económicos en el naciente pueblo. Los primeros quintales de café fueron enviados a San José por avión, el aeropuerto se convirtió en un punto valioso para el desarrollo de este pueblo, por mucho tiempo era la forma más ágil de llegar y salir en una emergencia al Valle Central y viceversa. Además, una estación de radio fungió como medio de comunicación con el Valle Central (Samper y Peters, 2001; Díaz \& Quesada-Román, 2016).

Con el fin de fomentar el desarrollo agrícola impulsado por los colonos italianos, el Estado costarricense autorizó la exención de impuestos de aduana para la adquisición de vehículos, maquinaria y repuestos destinados a San Vito (ANCR, Agricultura e Industrias, 608, 1960, f. 2168 y f. 2259). También, el extinto Banco Anglo Costarricense aportó fondos 
para el establecimiento de una Agencia de Extensión Agrícola en dicha localidad, con el fin de promover las actividades económicas basadas en la agricultura (ANCR, Agricultura e Industrias, 608, 1960, f. 2213). A partir de una entrevista realizada a Bernardo Valverde González (1919-2005), un colono puriscaleño que se instaló en el poblado de La Manchuria de Limoncito, destacan las diferencias respecto a la capacidad tecnológica y de recursos con que contaban los colonos italianos en relación con sus pares costarricenses:

Los italianos traían los almácigos [de café] de San José hasta San Vito en un camión que ellos tenían y remolcado con un tractor Caterpillar D-7; de esa misma manera transportaban también los víveres. Los colonizadores costarricenses cultivaban maíz amarillo y frijoles y para conseguir las semillas tenían que atravesar durante muchas horas la montaña para lograr llegar hasta Los Reyes (Ministerio de Cultura, Juventud y Deportes \& Centro de Investigación y Conservación del Patrimonio Cultural, 1990, p. 84).

El siguiente testimonio evidencia la rápida transformación del paisaje de las tierras donde se asentó la ciudad de San Vito:

En los años 1951-52 todo esto que forma el centro de un cantón próspero de 25.000 habitantes no era sino selva cerrada, sin un metro cuadrado de abra [...] En veinte años -ejemplo único en el país- se ha convertido la cerrazón de selvas en un enjambre humano que produce nada menos que 100.000 fanegas de un café de excelente calidad, y en donde el clima sano y la gente trabajadora y amable, conforman una admirable comunidad, con un futuro brillante (Club de Leones de Coto Brus, 1977, p. 26).

San Vito se convirtió en uno de los pocos casos de una colonia agrícola planificada que resultó exitoso en Costa Rica (Hall, 1983), gracias al esfuerzo emprendido por sus moradores que aprovecharon las condiciones propias del lugar que habitaban para consolidar una pequeña ciudad. En palabras del historiador Marvin Andrey Araya, la labor impulsada por la SICA produjo "el proceso de transformación más acelerado que hasta entonces experimentara una región en Costa Rica, convirtiendo una selva tropical en una zona cafetalera en poco más de una década" (Araya, 2017, p. 3). De esta manera, las tierras, donde se asentó el poblado de San Vito, cambiaron drásticamente de uso de suelo al ser deforestadas con el fin de emplearlas en la caficultura y el desarrollo urbano (Figura 2). 
Adolfo Quesada-Román - Ronald Díaz-Bolaños

Impactos ambientales de la colonización agrícola en Coto Brus, Costa Rica (1940-2018)

Figura 2: Desarrollo urbano y modificación del bosque a áreas de pastos y café alrededor del centro de San Vito en 1960 y 1973

1960

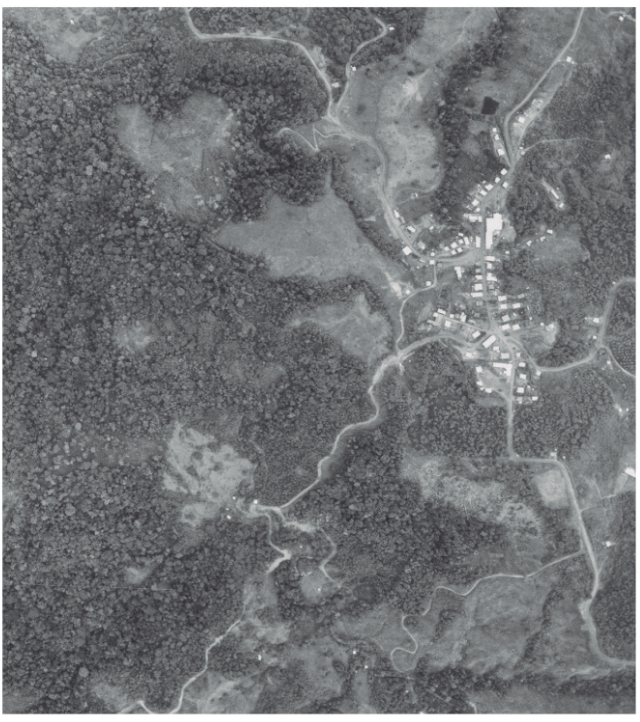

1973

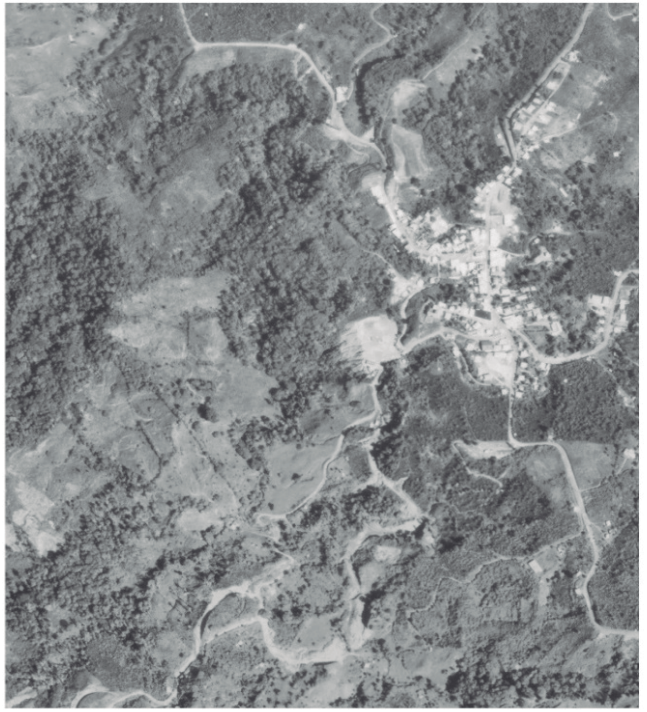

Fuente: IGN (1960); IGN (1973).

La presencia de dos beneficios en los principales poblados de Coto Brus, es decir San Vito y Sabalito, incentivó aún más el desarrollo de la actividad cafetalera, en una época en que los precios favorables con que se cotizaba el café en el mercado mundial favorecieron la apertura de nuevas fincas dedicadas al café en esta zona, particularmente en las altitudes medias y debido a las necesidades de transportar dicho producto, fue necesario el mejoramiento de los caminos (Pérez, 1997; Samper \& Peters, 2001).

La expansión del café para la década de 1960 trajo consigo un crecimiento rápido de la infraestructura de los pueblos de San Vito, Sabalito y Agua Buena, se empezó a gestar la idea de que debería crearse un cantón que reuniera los diversos poblados, en procura de un mejor apoyo estatal en la construcción de caminos e implementación de mejores servicios públicos como agua, electricidad, salud pública, entre otros, iniciativa que se cristalizó a mediados de ese decenio. 


\section{La consolidación de la agroindustria cafetalera en Coto Brus (1965-1990)}

Debido al aumento de la población y al creciente desarrollo de la producción cafetalera en la zona, el 10 de diciembre de 1965 se fundó el cantón de Coto Brus, cuya cabecera fue asignada a la localidad de San Vito. Este hecho permitió la instalación de un gobierno local en el nuevo cantón y un fortalecimiento de las actividades productivas en la zona.

Para la conformación del cantón se ejecutaron las siguientes leyes, decretos y acuerdos que dispusieron su creación y las modificaciones administrativas posteriores que aparecen en la Tabla 1.

Tabla 1. Legislación concerniente al cantón de Coto Brus

\begin{tabular}{|l|l|l|}
\hline Documento & Fecha & Descripción \\
\hline Ley 3598 & $\begin{array}{l}10 \text { de diciembre de } \\
1965\end{array}$ & $\begin{array}{l}\text { Creación y límites del cantón de } \\
\text { Coto Brus y sus distritos, segregado } \\
\text { de los cantones de Buenos Aires y } \\
\text { Golfito }\end{array}$ \\
\hline Decreto 25 & 7 de mayo de 1966 & Adscripción de caseríos a Coto Brus \\
\hline Ley 4339 & 2 de febrero de 1970 & $\begin{array}{l}\text { Creación y límites del cantón de } \\
\text { Talamanca, colindante con el de Coto } \\
\text { Brus }\end{array}$ \\
\hline Ley 4574 & 4 de mayo de 1970 & $\begin{array}{l}\text { San Vito adquiere el título de ciudad } \\
\text { por mandato del Código Municipal }\end{array}$ \\
\hline Ley 5373 & 19 de octubre de 1973 & $\begin{array}{l}\text { Modificación del límite sur de } \\
\text { Coto Brus al crearse el cantón de } \\
\text { Corredores, colindante con este } \\
\text { cantón }\end{array}$ \\
\hline Acuerdo 428 & $\begin{array}{l}29 \text { de noviembre de } \\
1988\end{array}$ & $\begin{array}{l}\text { Creación y límites del distrito 5 } \\
\text { Pittier, además rectifica límites de los } \\
\text { demás distritos }\end{array}$ \\
\hline $\begin{array}{l}\text { Acuerdo Ejecutivo } \\
45-2014-M G P\end{array}$ & 31 de julio de 2014 & $\begin{array}{l}\text { Creación y límites del distrito 6 } \\
\text { Gutiérrez Braun }\end{array}$ \\
\hline
\end{tabular}

Fuentes: Instituto Geográfico Nacional (2009). Poder Ejecutivo (2017, 8 de marzo). Cantón 608: Coto Brus. Alcance 52, La Gaceta (Costa Rica). 
La agroindustria cafetalera se consolidó como la principal actividad productiva en el joven cantón de Coto Brus y se dio en el marco de las políticas desarrollistas impulsada por el Estado benefactor en Costa Rica. Durante los primeros años del establecimiento de San Vito, antes de la fundación del cantón de Coto Brus (1952-1965), los colonos trabajaban sus tierras y progresivamente iban pagando sus deudas a la SICA con la producción que iban sacando en sus fincas, muchos italianos no lograron pagar sus deudas y debieron volver a Italia, así que otros colonos fueron adquiriendo más y más tierras, cerca y fuera del centro de San Vito creando grandes fincas (Hall, 1983; Weizmann, 1987; Manger, 1992).

Sin embargo, el precio del café tendió a bajar y no generaba las ganancias esperadas en la década de 1960, por lo que a veces los colonos de San Vito, si acaso pagaban sus deudas. No obstante, para este decenio el nuevo cantón fue un punto altamente atractivo para personas que querían comprar tierras baratas o hasta quedaban algunas pocas tierras baldías que podían ser colonizadas aún más hacia el norte de su territorio, al pie de la Cordillera de Talamanca. Los distintos pueblos del cantón de Coto Brus fueron altamente llamativos para familias colonizadoras, en búsqueda de nuevos rumbos, muchos grupos familiares de la Zona de los Santos, además de cantones alajuelenses como Atenas, Grecia y Naranjo, así como diversos lugares del país, entre ellos la provincia de Guanacaste, emigraron hacia el cantón (Pérez, 1997; Díaz \& Quesada-Román, 2016).

La década de los setentas fue provechosa para Coto Brus porque se presenta un repunte importante en los precios del café como resultado del impacto de la helada que afectó a la producción brasileña a mediados de dicho decenio (Pérez, 1997). En el año de 1975 se pagó a \$71.73 el quintal, para 1976 fueron $\$ 141.96$ y en el año de 1977 creció vertiginosamente a \$229.21; en este último año muchas personas hicieron grandes ganancias y se construyeron numerosos edificios que aún están en el centro urbano de San Vito, por lo que ese año fue de un gran empuje para el desarrollo de este cantón sureño (Sansonetti, 1995).

La producción de café crecía de nuevo con rapidez, debido a que el cantón empezó a percibir mayores ingresos de la venta del grano al exterior. Muchas de las grandes fincas que fueron fundadas por los colonos u otorgadas por el Estado, rápidamente fueron fraccionadas dando lugar a un 
mayor número de personas dedicadas en su totalidad a las actividades agrícolas, exceptuando los pocos comercios existentes que se establecieron en los centros urbanos (San Vito, Sabalito y Agua Buena). Esta división de vastas áreas de tierras que se vendían o quedaban a merced de colonos promovió una mejor utilización de los recursos naturales disponibles y fomentó una relativa estabilidad social entre los agricultores. Por supuesto, algunos colonos italianos y costarricenses se movieron ágilmente e hicieron crecer sus propiedades añadiendo nuevos lotes por medio de la compra a veces por remate a bajos precios.

Para la década de 1980, la ciudad de San Vito se fue consolidando como el principal centro urbano de este cantón puntarenense: "La zona de San Vito ha crecido con un patrón de agricultura muy parecido al del Valle Central o de San Isidro de El General; zona de altura, (alrededor de 1.000 metros sobre el nivel del mar), de cafetales, de población dispersa, de pequeña propiedad, de muchos caminos vecinales, de muchos lugares con nombres pero que no alcanzan a constituir un pueblo" (Morales \& Romero, 2000, p. 76). A raíz de la debacle económica generada por el retiro de la Compañía Bananera de Costa Rica en la zona costera sur en 1984, una parte de la población afectada se trasladó al cantón de Coto Brus en busca de trabajo en las actividades agrícolas que se desarrollan en su territorio, lo que contribuyó al aumento de su población (Morales \& Romero, 2000).

Un factor que condicionó el desarrollo de este cantón fue que sus principales centros urbanos (San Vito, Sabalito y Agua Buena), se encuentran alejados de la Carretera Interamericana y, por ende, de otros centros poblacionales importantes, siendo Ciudad Neily el más próximo y distante unos 30 kilómetros al sur de San Vito y tiene como limitante que la vía que los comunica atraviesa la Fila de Cal. Además, de San Vito a San Isidro de El General, la principal ciudad del sur de Costa Rica hay una distancia de unos 150 kilómetros, y hasta 1994, se hacía necesario cruzar por ferry el Río Grande de Térraba a la altura de Paso Real. De esta forma, las dificultades en las comunicaciones terrestres hicieron que el dinero que se generaba en el cantón de Coto Brus se quedaba principalmente ahí y circulara dentro de los mismos comercios existentes, lo que permitió obtener recursos para el crecimiento económico local porque se reinvertía a través de un ciclo económico retroactivo (Morales \& Romero, 2000; Díaz \& Quesada-Román, 2016). 
Este periodo fue el de las épocas de mayor deforestación en el cantón, donde según el estudio de Zahawi, Durán \& Kormann (2015) entre los años 1947 y 2014, para un sector de influencia directa de la Estación Biológica Las Cruces -situada al sur de San Vito - de $13 \mathrm{~km}$ a la redonda, se perdieron 22,538 hectáreas de bosque en tan sólo 67 años, lo que equivale a una pérdida del total del área boscosa en un $70.3 \%$. Las altas tasas de deforestación del cantón eran congruentes con la tendencia nacional (Rosero-Bixby \& Palloni, 1998). Además, los rápidos cambios en los usos de la tierra han provocado altas tasas de erosión que se han reflejado a escala regional en las variaciones de erosión y acumulación de sedimentos en el Humedal Nacional Térraba-Sierpe en los últimos 70 años (Acuña-Piedra \& Quesada-Román, 2016; Acuña-Piedra \& Quesada-Román, 2017).

Los usos de la tierra típicos de Coto Brus una vez abierta la frontera agrícola fueron el tridente de café, pastos y bosques (Figura 3). Estos usos se alternaron dependiendo del distrito en que se localizaron y el empuje o atracción económica hacia una actividad temporal. Esto obedecía a la oferta y demanda de productos como la carne y el café, los cuales no tienen precios constantes y sus variaciones indicaban los pulsos de mayor crecimiento/decrecimiento de sus áreas, según estas variables macroeconómicas nacionales e internacionales (Díaz \& Quesada-Román, 2016).

Los problemas ambientales más recurrentes fueron las altas tasas de erosión en todo el cantón, dado el elevado nivel de deforestación y apertura de campos para el cultivo; además producto del mismo beneficiado (procesamiento) del café y el mal tratamiento de las aguas oleaginosas se provocaron importantes afectaciones en las condiciones naturales de ríos y quebradas del cantón, especialmente en la flora y fauna de los cuerpos de agua, los cuales no han vuelto a ser los mismos (Quesada-Román \& Mora-Vega, 2017). Además, para este período no se conocen en detalle otros impactos en el medio como la modificación de la temperatura media, la media de precipitación y otras variables microclimáticas que podrían traer problemáticas aún mayores en los ecosistemas, la carga acuífera en el futuro para las comunidades y la contaminación de fuentes de agua. 
Figura 3: Paisaje típico de Coto Brus para la década de 1960

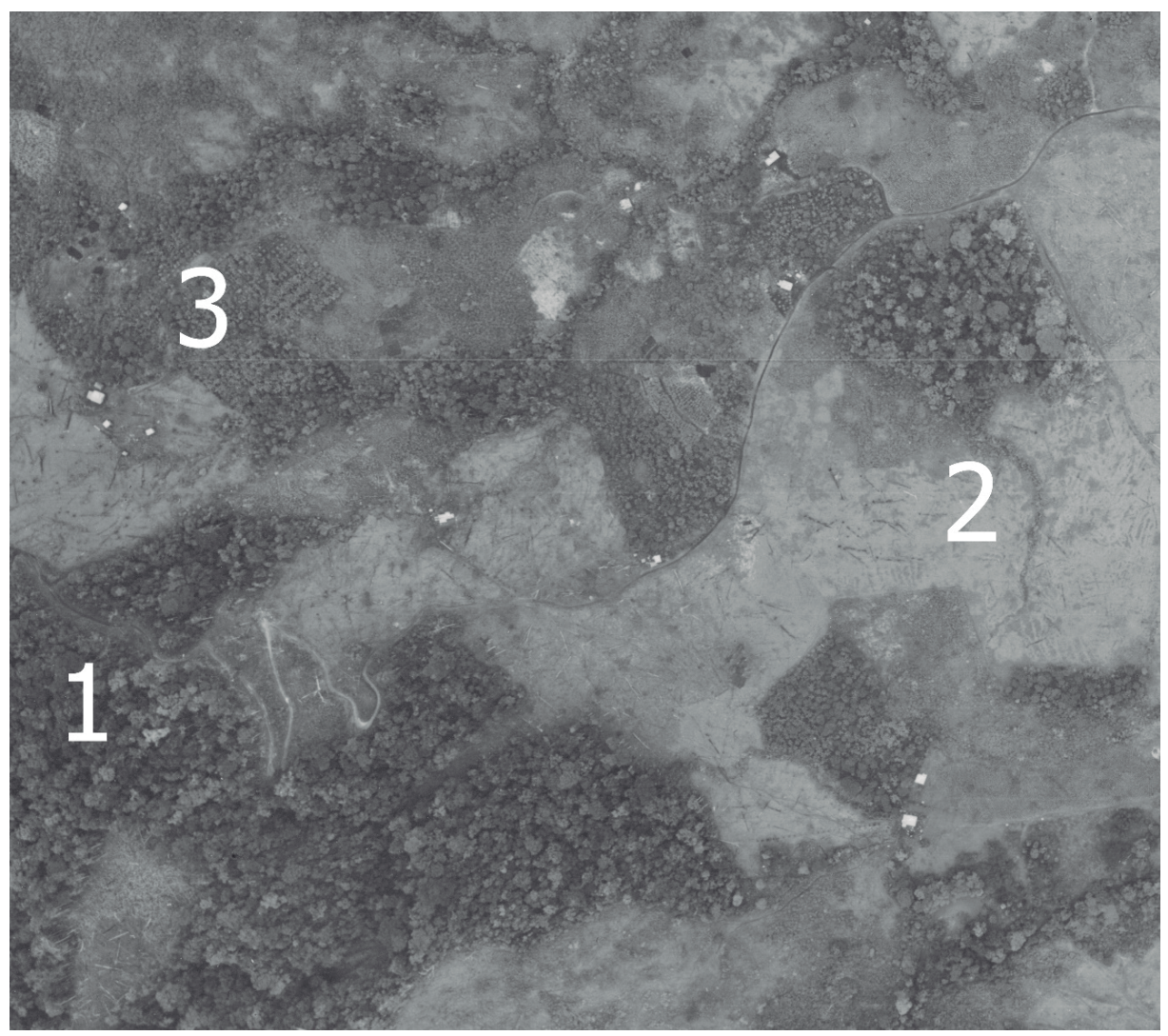

1.Bosques, 2. Pastos, 3. Café. Este patrón se mantiene hasta la actualidad con la variante de café por otros cultivos. La fotografía aérea corresponde a Santa Teresa de Sabalito.

Fuente: IGN (1960).

\section{La diversificación de la actividad productiva en Coto Brus (1990-2018)}

A partir de la década de 1990 y fruto de las políticas de "Volvamos a la Tierra" de la administración de Luis Alberto Monge (1925-2016), entre 1982 y 1986 y la denominada "agricultura de cambio" en la primera administración de Oscar Arias (1986-1990), impulsadas por el Estado costarricense como parte del modelo económico neoliberal en el contexto de los Programas de Ajuste Estructural (PAE) (Molina \& González, 2015; Díaz \& Quesada-Román, 2016), las tierras de Coto Brus comenzaron a 
experimentar un proceso de diversificación agrícola, en sintonía con las fluctuaciones del precio del café en el mercado mundial, lo que ha traído consecuencias para el desarrollo de la agroindustria cafetalera en los últimos lustros a nivel nacional y local, ya que no generaría los ingresos suficientes para promover un desarrollo más equitativo del cantón y favorecería una recuperación de la cobertura vegetal (Figura 4).

Figura 4: Aumento de la mancha urbana y de la frontera agrícola en los alrededores de San Vito de Coto Brus.

1980

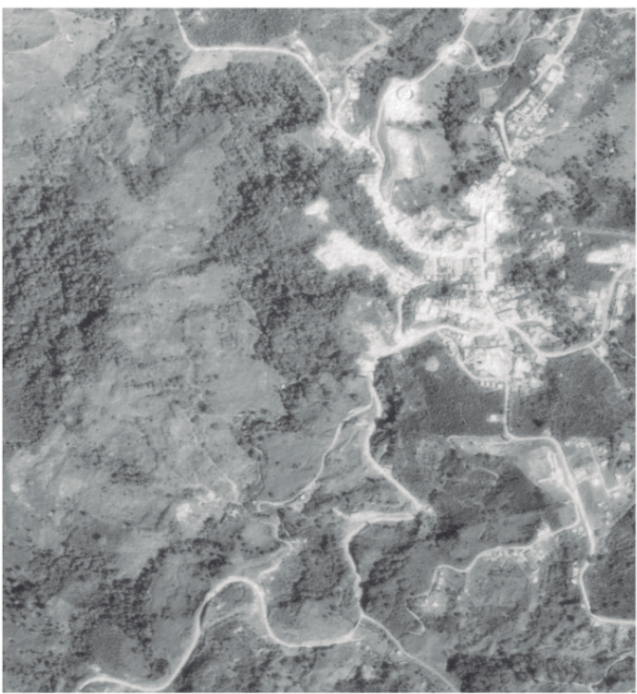

Fuente: IGN (1980); IGN (1992).
1992

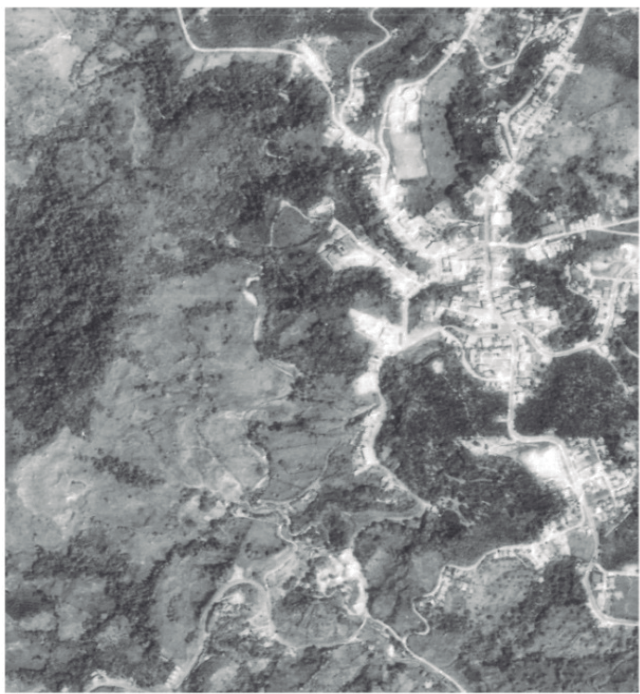

No obstante, la expansión del café en los decenios anteriores favoreció el surgimiento de una especialización productiva (Figura 5), especialmente en los alrededores de San Vito, tendiente "a un monocultivo que atrae mano de obra de las tierras bajas [de la Zona Sur] durante la cosecha, pero que obliga a la población local a migraciones de trabajo hacia otras regiones del país cuando decrece la actividad cafetalera" (Morales \& Romero, 2000, p. 206). Además, empleó también mano de obra indígena, particularmente ngöbe y buglé, tanto residente en el cantón en el Territorio Indígena de Coto Brus, como procedente de la vecina Panamá, por lo que 
deben desplazarse a los cafetales para laborar en tiempos de la recolección del café (Edelman \& Seligson, 1994; Samper \& Peters, 2001).

Las diversas actividades que durante este periodo se observaron en el cantón y sectores cercanos que contribuyen de manera indirecta con su economía (ciertas zonas aledañas pertenecientes a los cantones vecinos de Corredores y Buenos Aires) han sido el desarrollo del cultivo de múltiples tubérculos y raíces como el tiquizque y el ñampí, ambos productos de alta demanda temporal, donde no han mediado los estudios técnicos y de mercado oportunos para limitar el desenfreno por sembrar productos poco conocidos en la región y que a la postre han provocado pérdidas y la ruina de múltiples familias.

Por otro lado, en ciertas regiones muy puntuales del cantón durante este periodo se ha visto un incremento de los sembradíos de caña india como producto alterno dentro de los cafetales, en cercas de potreros y propiedades privadas, producto que se exporta por medio de compañías como CoopeIndia de Palmares de Alajuela, empresa que envía estas plantas especialmente a los Estados Unidos para fines ornamentales.

Figura 5. Diversificación agrícola al noroeste de Coto Brus

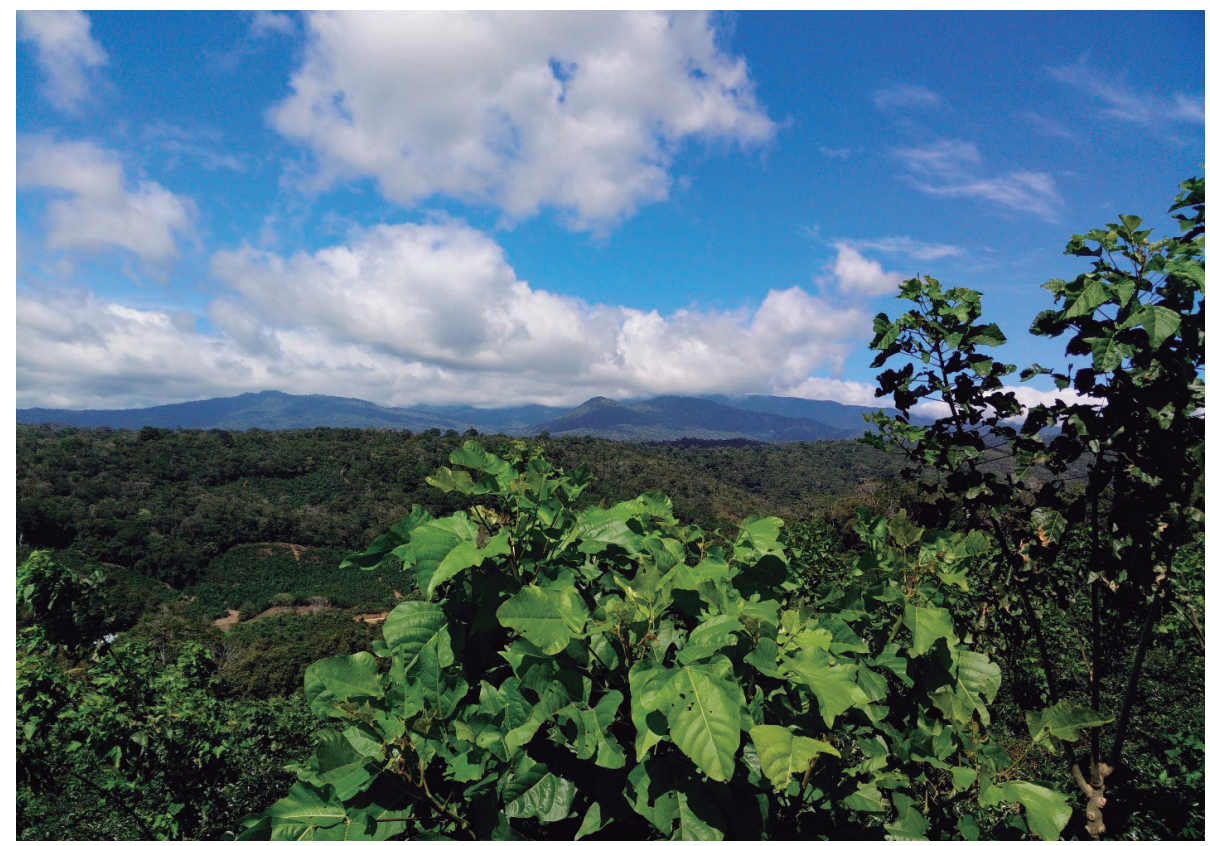


Este paisaje está compuesto por amplias extensiones de café en alternancia con áreas protegidas como la Zona Protectora Las Tablas. Se observan las estribaciones montañosas de la Cordillera de Talamanca y el Parque Internacional La Amistad. Fuente: Adolfo Quesada-Román, diciembre de 2015.

Otros de los productos que durante este periodo se han mantenido constantes son las hortalizas. Coto Brus, dadas sus características de suelos con influencia de cenizas del volcán Barú en Panamá (Ramírez \& Mata, 2003), posee las condiciones idóneas para el desarrollo de estos cultivos, especialmente hacia el este del cantón en el distrito de Sabalito y Agua Buena (dada su cercanía con la frontera).

Cabe mencionar que en este periodo hay una caída estrepitosa de las áreas cultivadas de café, lo que ha permitido por un lado la reforestación natural por la no renovación de estos terrenos o su pronta incorporación a otras actividades agrícolas o pastoriles. En cuanto al bosque primario, este queda principalmente reducido a las partes más bajas de los cursos de los ríos o a los sectores montañosos de más difícil acceso (Morales \& Romero, 2000). Dicho sea de paso, el Estado costarricense ha propiciado desde la década de 1970, una política de protección de la flora y la fauna característica de esos espacios que han sido escasamente alterados por la presencia humana a nivel nacional y en cuanto al cantón de Coto Brus, destaca el establecimiento de áreas protegidas bajo diversas características de manejo como la Zona Protectora Las Tablas (1981), el Parque Internacional La Amistad (1982), ambos situados en la cordillera de Talamanca y los humedales de San Vito (1994) y Palustrino Laguna del Paraguas (1994), además de la Estación Biológica Las Cruces (1973) y el Jardín Botánico Wilson (1963), estas últimas con carácter privado (Meza, 2001; Camacho, 2008).

De acuerdo con Quesada-Román (2013), para el año 2005 las áreas de bosques eran las que dominaban en el distrito de San Vito, el cual constituía el $36.5 \%$ del área total, seguido de pastos (33.3\%), cultivos permanentes $(26.9 \%)$ y otros usos con aproximadamente un cuatro por ciento. Esta unidad político-administrativa da un panorama general de la situación del resto del cantón donde las características de uso de la tierra son similares. Además, este autor indica que hay un $50 \%$ del distrito con uso correcto de la tierra, el subuso representa un $30 \%$ e indica valores de uso de la tierra por debajo de la capacidad de uso de la misma y no presentan 
actualmente un peligro de degradación de los terrenos, pero sí es importante aprovechar el potencial de los mismos. El sobreuso comprende un $20 \%$ del territorio, en el cual los procesos de degradación de las tierras van en contra de la fertilidad del suelo, la pérdida de los ecosistemas e inciden en la pérdida de la productividad agropecuaria (Figura 6).

Figura 6: Recuperación de algunas áreas boscosas que anteriormente fueron pastos al oeste de San Vito. Además, se observa la ocurrencia de múltiples procesos gravitacionales hacia el suroeste del centro del poblado.

\section{5}

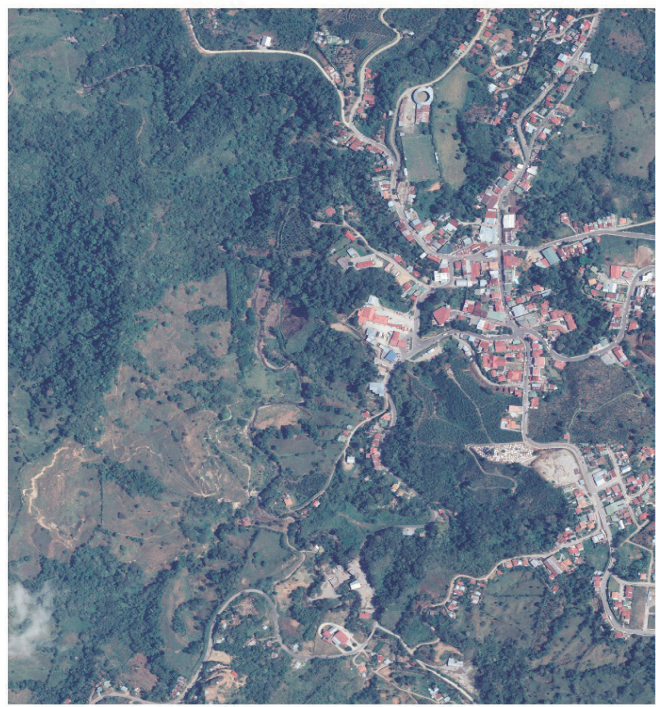

2018

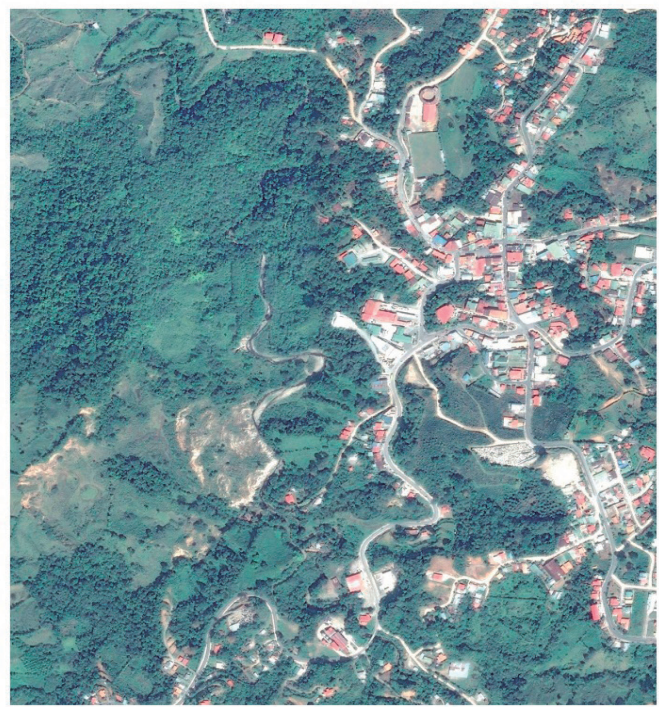

Fuente: CARTA (2005); Google Earth (2018).

Entre los problemas ambientales que este tipo de cultivos y actividades agropecuarias podrían generar son las altas cantidades de agroquímicos utilizados, los cuales son capaces de contaminar los mantos acuíferos y aguas superficiales afectando la biota de los ecosistemas existentes. Por otro lado, las tasas de erosión se mantienen altas, dado que no se cultiva en curva de nivel y se propicia un uso intensivo del territorio para fines agropecuarios que generen réditos económicos en poco tiempo. Es importante 
también indicar que se observa en recorridos constantes a diferentes zonas del cantón, como los procesos de reptación (pie de vaca) en áreas de pastos, cada vez son mayores, lo que tiene asociación directa con la pérdida de nutrientes del suelo, una mayor incidencia de deslizamientos y la degradación de las tierras.

\section{Conclusiones}

Las tierras que constituyen el actual cantón de Coto Brus presentan las condiciones adecuadas para el desarrollo rural en un territorio ubicado junto a la frontera con Panamá. Debido a la distancia que lo separaba del Valle Central y a la indefinición del límite internacional, primero con Colombia y a partir de 1903 con Panamá, favoreció la penetración de colonos chiricanos que se encuentran entre los primeros habitantes (después de las poblaciones indígenas anteriores al proceso de Conquista) en ocupar dicho espacio en las décadas que precedieron a la fundación del cantón.

La demarcación de la frontera con Panamá y el proyecto original de trazar la Carretera Interamericana en el Valle de Coto Brus, fue un aliciente para la colonización de un territorio que empieza a experimentar cambios en el uso de la tierra en el decenio de 1940. De esta forma, los nuevos colonos procedentes del interior del país, al igual que sus predecesores indígenas y chiricanos, comienzan a abrir caminos que les permitieron penetrar en las tierras que estaban ocupando.

El establecimiento del asentamiento de Sabalito en la década de 1940 y el de San Vito en 1952, que inició como una colonia italiana supuso el cambio del uso de la tierra con la introducción de actividades agrícolas en zonas cubiertas por bosques, que comenzaron a ser modificadas en la medida que fue creciendo el número de colonos. En el caso de San Vito, gracias al impulso de los inmigrantes italianos, la pequeña colonia se fue transformando con el paso de los años; el crecimiento de su infraestructura urbana le permitió convertirse en la cabecera cantonal y en el núcleo de una floreciente agroindustria basada en la producción cafetalera, que se convirtió en la principal actividad económica de la zona y transformó significativamente el paisaje rural de Coto Brus.

El esquema típico del crecimiento de la frontera agrícola que experimentó el cantón de Coto Brus desde antes de su fundación se basó en el cambio en el uso de la tierra de bosques a pastos y café, la llegada 
de tecnologías de mayor eficiencia como la motosierra favoreció un incremento de las tasas de deforestación que llegaron a ser las más altas a nivel nacional entre la década de 1960 y 1970, cuando se experimentó un importante flujo migratorio de colonos procedentes del Valle Central y otras zonas del país, que contribuyeron con el incremento demográfico de la población cotobruseña.

La paulatina implementación de políticas a nivel nacional en materia ambiental a partir de la década de 1980 y su consolidación en el decenio de 1990 permitió que las altas tasas de deforestación mermaran de cierto modo. Otras situaciones que favorecieron esta condición son los inestables precios internacionales y nacionales del café y de la carne, respectivamente. El tridente típico de usos de la tierra para Coto Brus, dadas sus condiciones geomorfológicas, edáficas, climáticas y ecosistémicas, son la asociación de café (o cultivos temporales), pastos y bosques. Este patrón favoreció la fragmentación de los bosques y pone un importante reto para la conectividad de áreas protegidas, tanto estatales como privadas que se han establecido en tierras cotobruseñas.

La realización de estudios posteriores podrían evidenciar, con un mayor nivel de profundidad, los impactos ambientales generados por la colonización agrícola en Coto Brus, a nivel local, distrital y cantonal, especialmente en relación con la deforestación causada por las nuevas actividades económicas, en particular la agroindustria cafetalera, así como su afectación en los recursos hídricos presentes en el cantón, como también el impacto generado por la creciente urbanización que se ha desarrollado principalmente en el distrito de San Vito.

Por último, sería pertinente analizar en futuros estudios la relación entre las condiciones atmosféricas y los ecosistemas presentes en Coto Brus - en especial en las zonas protegidas - así como su asociación con el cambio y la variabilidad climática, que se ha ido detectando también en este cantón, como lo han puntualizado Granados, Porras \& Calvo (2017) al estudiar el impacto ocasionado por fenómenos hidrometeorológicos recientes en la actividad cafetalera, que a pesar de la diversificación económica experimentada en dicho espacio, sigue siendo una de las más importantes en este territorio fronterizo en la Zona Sur de Costa Rica. 
Adolfo Quesada-Román - Ronald Díaz-Bolaños

Impactos ambientales de la colonización agrícola en Coto Brus, Costa Rica (1940-2018)

\section{Agradecimientos}

Esta investigación se realizó con el apoyo del Programa Estudios Sociales de la Ciencia, la Técnica y el Medio Ambiente (PESCTMA) del Centro de Investigaciones Geofísicas (CIGEFI) de la Universidad de Costa Rica. Un avance de la misma se presentó en el marco del XIII Congreso Centroamericano de Historia, celebrado en Tegucigalpa en julio de 2016. Los autores agradecen a la Sociedad Dante Alighieri de San Vito por el aporte de una fotografía para la presente investigación, así como a Marvin Andrey Araya Arias, Edgardo Gallo Guzmán y Valeria Mora López en la búsqueda de fuentes documentales y trabajos realizados sobre Coto Brus y a Mónica Aguilar Mejía por su colaboración en el proceso de revisión del artículo.

\section{Referencias}

Acuña-Piedra, J. F. \& Quesada-Román, A. (2016). Evolución geomorfológica entre 1948 y 2012 del delta Térraba-Sierpe, Costa Rica. Cuaternario y Geomorfología, 30 (3-4), 49-73. Recuperado de https:// doi.org/10.17735/cyg.v30i3-4.53055

Acuña-Piedra, J. F. \& Quesada-Román, A. (2017). Cambios en el uso y cobertura de la tierra entre 1948 y 2012 en el Humedal Nacional Térraba-Sierpe, Costa Rica. Revista Ciencias Marinas y Costeras, 9 (2), 9-28. Recuperado de http://dx.doi.org/10.15359/revmar.9-2.1

Amador, J. L. (2008). ¡Corre sangre chiricana por las venas del Sur! Elementos para interpretar la construcción de una región. El caso de Potrero Grande. Diálogos Revista Electrónica de Historia, Número Especial, 2272-2297. Recuperado de https://doi.org/10.15517/dre. v9i0.31424

Araya, A. (2017). El Pacifico sur costarricense: análisis de la formación de su estructura de tenencia agraria y de la evolución del espacio económico (1884-1963). (Tesis de Licenciatura en Historia), Universidad de Costa Rica.

Archivo Nacional de Costa Rica (ANCR), Agricultura e Industrias, 608 (1960).

Arias, D. (2007-2008). Aproximación al estudio de la historia del cantón de Osa (1914-1990). Diálogos - Revista Electrónica de Historia, 8(2), 78-123. Recuperado de http://hdl.handle.net/10669/19317 
Bariatti, R. (1989). Inmigrantes italianos en Costa Rica: Estudio de su integración mediante fuentes orales. Revista de Historia, 20, 105-131. Camacho, M. N. (2008). Encuentro con un paraíso natural: Estación Biológica Las Cruces Jardín Botánico Wilson. Biocenosis, 21(1-2), 77-80. CARTA - Costa Rica Airborne Research and Technology Applications. (2005). Fotos aéreas 1:25000 de Costa Rica. NASA (USA) y Gobierno de Costa Rica.

Chinchilla, E. (1987). Atlas Cantonal de Costa Rica. San José, Costa Rica. Instituto de Fomento y Asesoría Municipal (IFAM).

Clement, R.M. \& Horn. S.P. (2001). Pre-Columbian land-use history in Costa Rica: a 3000-year record of forest clearance, agriculture and fires from Laguna Zoncho. The Holocene, 11 (4), 419-426.

Club de Leones de Coto Brus. (1977). Bodas de plata: San Vito de Java 1952-1977. Litografía Caribe S.A. San José, Costa Rica.

Díaz, R. E. (2013). El aporte del conocimiento geográfico en la invención de la identidad nacional en Costa Rica (1833-1944). (Tesis de Maestría en Historia), Universidad de Costa Rica.

Díaz, R. E. \& Quesada-Román, A. (2016). El impacto socioambiental de la actividad cafetalera en el cantón de Coto Brus, Costa Rica (19402015). Lértora, C. (coord.). Proyecto EcoEpisteme. Las disciplinas ambientales frente a los desafios actuales. Buenos Aires. FEPAI: 155-172.

Díaz, R. E. \& Salazar, Y. J. (2017). Historia de Costa Rica para el turismo. San José, Costa Rica: EUNED.

Edelman, M. \& Seligson, M. A. (1994). La desigualdad en la tenencia de la tierra: Una comparación de los datos de los censos y de los registros de propiedad en el Sur de Costa Rica en el siglo XX. Anuario de Estudios Centroamericanos, 20 (1): 65-113.

Gagini, C. (1917). Los aborígenes de Costa Rica. San José, Costa Rica: Tipografía Trejos Hnos.

Google Earth. (2018). Imágenes satelitales de San Vito de Coto Brus.

Granados, R. E., Porras, A. J. \& Calvo, Ó. D. (2017). ¿Cambio climático o variabilidad climática en Coto Brus?: controversias sobre las perspectivas de los efectos de la tormenta tropical Nicole y el huracán Thomas en el cultivo del café. Revista Española de Estudios Agrosociales y Pesqueros, 246, 31-60. 
Gutiérrez, J. R. (2002). La gloria de dos titanes: la historia que no se ha contado. San José, Costa Rica: Editorial Garabito.

Hall, C. (1983). Costa Rica, una interpretación geográfica con perspectiva histórica. San José, Costa Rica: Editorial Costa Rica.

Hilje, B. (1991). La colonización agrícola de Costa Rica (1840-1940). San José, Costa Rica: EUNED.

Instituto Geográfico Nacional (IGN). (1960). Fotografías aéreas de San Vito a Sabalito escala 1:5000.

Instituto Geográfico Nacional (IGN). (1973). Fotografías aéreas de San Vito escala 1:20000.

Instituto Geográfico Nacional (IGN). (1980). Fotografías aéreas de San Vito escala 1:40000.

Instituto Geográfico Nacional (IGN). (1992). Fotografías aéreas de San Vito escala 1:60000.

Instituto Geográfico Nacional (IGN). (1989). Edición conmemorativa. Cien años. Instituto Geográfico Nacional. San José, Costa Rica: Instituto Geográfico Nacional.

León, J. (1952). Nueva Geografía de Costa Rica. San José, Costa Rica: Librería La Española.

Manger, W. (1992). Colonization on the southern frontier of Costa Rica: a historical cultural landscape. (Magister Science Thesis), Memphis State University.

Meza, T. (2001). Geografía de Costa Rica. Cartago, Costa Rica: Editorial Tecnológica de Costa Rica.

Ministerio de Cultura, Juventud y Deportes. Centro de Investigación y Conservación del Patrimonio Cultural (1990). La Historia del Pacífico Sur contada por sus pobladores. San José, Costa Rica: MCJD.

Molina, S. E. \& González, E. (2015). Historia de Costa Rica. San José, Costa Rica: EUNED.

Morales, M. \& Romero, R. (2000). Crisis del Estado nacional hacia el siglo XXI: La cuestión fronteriza Costa Rica, Nicaragua y Panamá. Heredia, Costa Rica: Programa de Publicaciones e Impresiones de la Universidad Nacional.

Morera, C. \& Meléndez, S. (2017). La presencia de los chiricanos en el Pacífico Sur de Costa Rica: aportes desde la Geografía Histórica. 
Revista Geográfica de América Central, 59, 65-90. Recuperado de $\mathrm{http}: / / \mathrm{dx}$.doi.org/10.15359/rgac.3-59.3

Mörne, H.A. (2001). El camino que lleva a Costa Rica. Quesada, M. Á. (comp.). Entre silladas y rejoyas. Viajeros por Costa Rica de 1850 a 1950. (732-798). Editorial Tecnológica de Costa Rica. Cartago, Costa Rica.

Naranjo, C. (s.f.). Conquistando el Sur: Una Breve Historia de la Colonización Agrícola de los Valles de Coto y Cañas Gordas. Informe de investigación. Código de proyecto: 021039-01. Heredia, Costa Rica: Escuela de Historia, Universidad Nacional.

Pérez, H. (1997). Breve historia contemporánea de Costa Rica. Fondo de Cultura Económica. México.

Poder Ejecutivo (2017, 8 de marzo). Cantón 608: Coto Brus. Alcance 52, La Gaceta (Costa Rica). Recuperado de https://www.imprentanacional.go.cr/pub/2017/03/08/ALCA52_08_03_2017.pdf.

Quesada-Román, A. (2013). Condición de uso de la tierra del distrito San Vito, Coto Brus, Puntarenas. Revista Reflexiones, 92 (1), 47-64.

Quesada-Román, A \& Mora-Vega, A. (2017). Impactos ambientales y variabilidad climática en el humedal de San Vito, Coto Brus, Costa Rica. Revista de Ciencias Ambientales, 51 (1), 16-32. Recuperado de http://dx.doi.org/10.15359/rca.51-1.2

Ramírez, J. E. \& Mata, R. A. (2003). Caficultura de Coto Brus. Antecedentes, suelos y manejo del cultivo. Instituto del Café de Costa Rica. San José, Costa Rica.

Rosero-Bixby, L. \& Palloni, A. (1998). Population and Deforestation in Costa Rica. Population and Environment, 20(2), 149-185. Recuperado de http://dx.doi.org/10.1023/A:1023319327838

Samper, M. \& Peters, G. (2001). Café de Costa Rica. Un viaje a lo largo de su historia. San José, Costa Rica: ICAFE.

Sánchez, E. (2011). Corredores: una historia por reelaborar (1920-1980). Abarca, O.; Bartels, J.; Chen, S. y Marín, J. J. (eds., comps.). Poder, colonización y arquitectura. Región del Pacifico Costarricense: 1780-1920 (pp. 157-182). San José, Costa Rica: Sociedad Editoria Alguimia 2000. 
Sansonetti, V. (1995). Quemé mis naves en estas montañas: la colonización de la altiplanicie de Coto Brus y la fundación de San Vito de Java. Editorial Jiménez \& Tanzi. San José, Costa Rica.

Sibaja, L. (1968). El límite sureste de Costa Rica. Reseña histórica desde el laudo Loubet hasta su fijación definitiva. (Tesis de Licenciatura en Historia), Universidad de Costa Rica.

Sistema Costarricense de Información Jurídica (s.f.). Aprobación del Contrato suscrito entre el Gobierno de la Repúblicay la Sociedad Italiana de Colonización Agrícola de Roma Italia. Ley 1316, 13 de julio de 1951. Recuperado de http://www.pgrweb.go.cr/scij/Busqueda/Normativa/ Normas/nrm_texto_completo.aspx?nValor1=1\&nValor2=3307.

Weizmann, H. G. (1987). Emigrantes a la conquista de la selva. Segunda Edición. San Vito, Costa Rica: Comité de la Sociedad Cultural «Dante Alighieri» de San Vito.

Zahawi, R., Durán, G. \& Kormann, U. (2015). Sixty-Seven Years of LandUse Change in Southern Costa Rica. PLoS ONE, 10(11), 1-17. Recuperado de https://doi.org/10.1371/journal.pone.0143554. 